\title{
Evaluation and correlation of placental vasculature by three- dimensional power Doppler ultrasonography with umbilical Doppler in normal and IUGR pregnancies
}

\author{
Sumesh Choudhary*, Vineet Mishra, Rohina Aggarwal, Kavita Mistry
}

Department of Obstetrics and Gynecology, Institute of Kidney Diseases and Research Centre, Ahmedabad, Gujarat, India

Received: 03 July 2018

Accepted: 27 July 2018

*Correspondence:

Dr. Sumesh Choudhary,

E-mail: drsumeshchoudhary@gmail.com

Copyright: () the author(s), publisher and licensee Medip Academy. This is an open-access article distributed under the terms of the Creative Commons Attribution Non-Commercial License, which permits unrestricted non-commercial use, distribution, and reproduction in any medium, provided the original work is properly cited.

\section{ABSTRACT}

Background: In recent years there have been significant developments in the use of 3D Power Doppler (3DPD) imaging and quantitative 3DPD histogram analysis to estimate both placental volume and intraplacental vasculature. This study is to evaluate the distribution and variation of placental vascular indices according to gestational age and placental volume and position. Co relate the umbilical Doppler indices with placental vascular indices.

Methods: From September 2016 to October 2017, three-dimensional (3D)-power Doppler ultrasound was performed in 200 singalton pregnancies from 20 to 40 weeks of gestation. Using the same pre-established settings for all patients, power Doppler was applied to the placenta and placental volume was obtained by the rotational technique (VOCAL). The 3D-power histogram was used to determine the placental vascular indices: vascularization index (VI), flow index (FI) and vascularization-flow index (VFI). Umbilical Doppler was measured on the free loop of umbilical cord. The placental vascular indices were then plotted against gestational age placental volume, position and umbilical Doppler SD ratio, PI and RI. These values were evaluated in IUGR fetus.

Results: Analysis of the results showed that the placental vascular indices estimated by 3D-power Doppler ultrasonography presented constant distribution throughout gestation despite the significant increase in placental volume. Placental position at fundal region shows higher value of VI, FI, and VFI. Placental position with relation to VI, FI, and VFI shows statistically significant with $p$ value $<0.01$. Placental vascular indices VI, FI and VFI when corelated with systolic/ diastolic ratio, pulsatility index and resistive resistance index of umbilical artery shows poor negative correlation, only VI and FI shows statistically significant with SD ratio as $\mathrm{p}$ value is $<0.01$ and $<0.04$. VFI did not show statistically significant as $\mathrm{p}$ value is $0.10(\mathrm{NS})$. With pulsatility index $\mathrm{p}$ value is statistically significant is less than $<0.01$ with vascular indices. Resistive index $\mathrm{p}$ value is statistically significant is less than $<0.01$ for VI and VFI but not significant with FI as p value is 0.06 .

Conclusions: Doppler ultrasound assists in the evaluation of placental vascularization in normal and IUGR pregnancies, may play an important role in future research on fetoplacental insufficiency.

Keywords: Three-dimensional power doppler, Placenta, Placental vascularity, Umbilical artery doppler

\section{INTRODUCTION}

Uterine and placental vascularizations are important for normal pregnancy development without question realtime evaluation of placental pathology will improve diagnosis and close monitoring of high-risk pregnancies. ${ }^{1,2}$ Abnormal maternal-fetal circulation can lead to increased flow resistance through the uterine circulation, causing placental insufficiency and decreased oxygen support to the fetus. ${ }^{3}$ In recent years there have 
been significant developments in the use of 3 dimensional (3D) Power Doppler imaging as seen in (Figure 1, 2 and 3) and quantitative 3D Power Doppler (3DPD) histogram analysis to estimate both placental volume and intraplacental vasculature. ${ }^{4}$

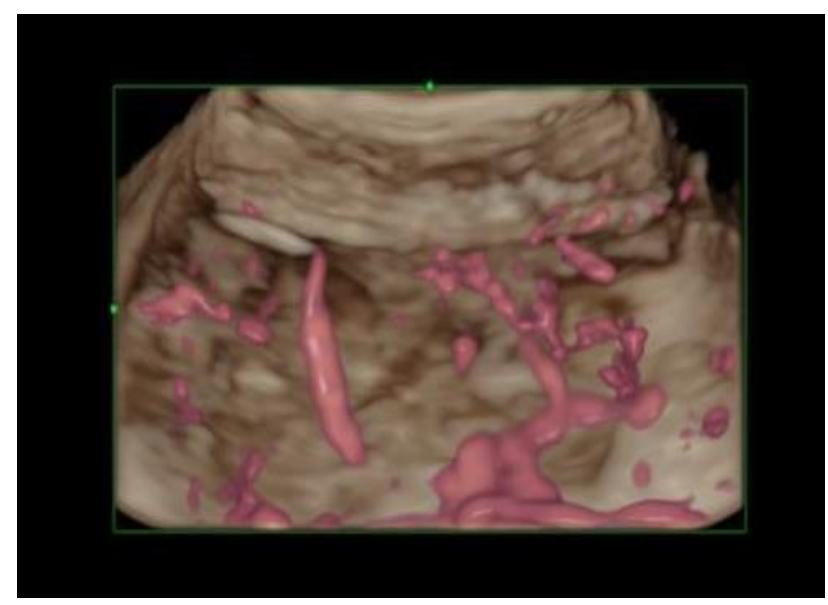

Figure 1: Placental vasculature seen in 3D Power Doppler.

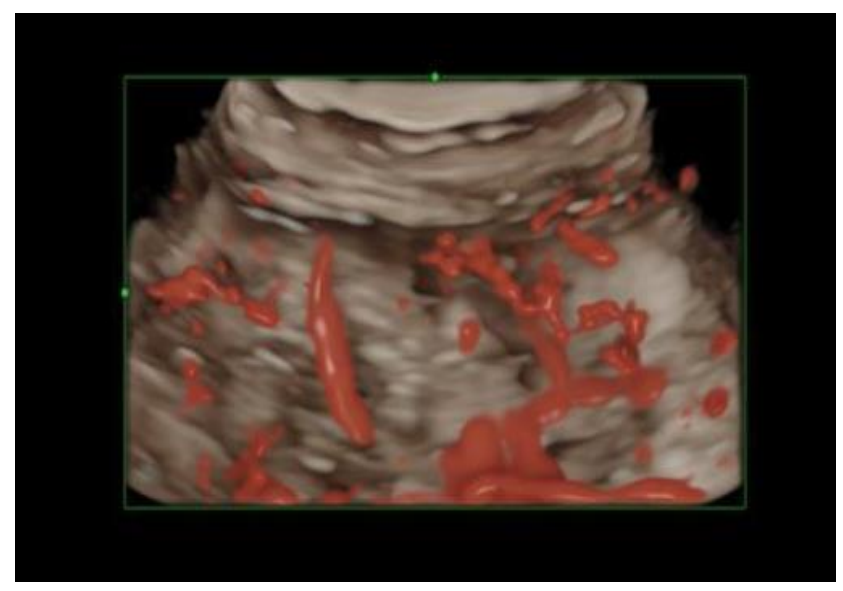

Figure 2: High definition view of placental vascularity.

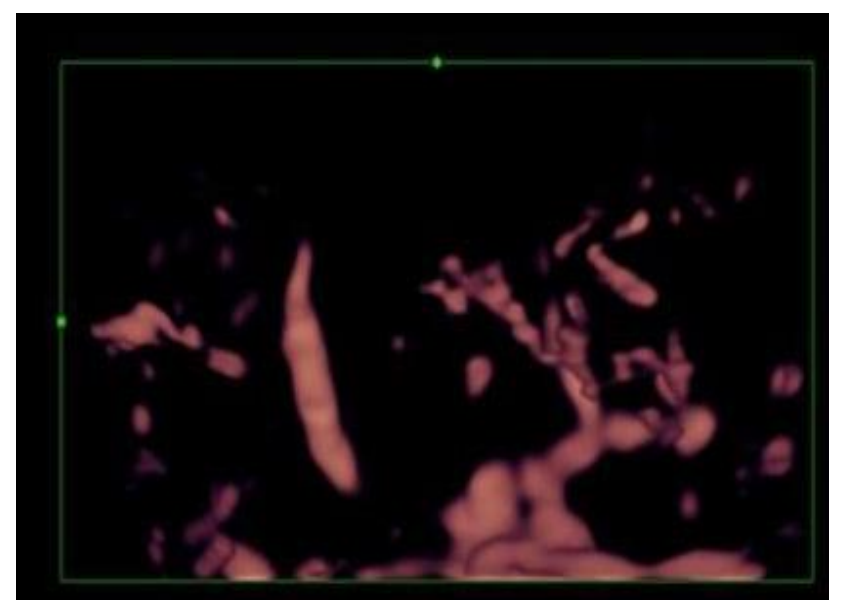

Figure 3: Angio mode view of placental vasculature.
The vascularisation index (VI) is an indicator of overall perfusion or vascularity, the flow index (FI) measures the intensity of blood flow at the time of the 3D sweep and the vascularisation-flow index (VFI) represents fractional moving blood volume. ${ }^{5}$ Abnormal placental development is associated with a few obstetrical adverse outcomes, such as fetal growth restriction, preterm labor, preeclampsia, fetal hypoxia and death. ${ }^{6}$ Quantitative assessment of placental vascularization may be useful for predicting these complications or diagnosing them earlier. Besides, studying the placental vascularization can also provide further information of the physiopathological process of increased resistance in umbilical arteries associated with placental insufficiency. ${ }^{7}$ However, little information exists in the literature regarding the distribution of these placental vascular indices throughout gestation. ${ }^{8}$ The present study prospectively evaluated placental vascular indices estimated using 3D Power Doppler ultrasonography in normal pregnancies and IUGR in order to evaluate their distribution according to gestational age and correlate with umbilical artery Doppler flow indices.

\section{METHODS}

Between September 2016 to October 2017, patients were recruited at prenatal care unit of our department. All the women volunteered to undergo ultrasound examination after being fully familiarized with the study protocol and the technique. Inclusion criteria were all women with singleton pregnancies, normal fetal morphological ultrasound exams and reliable pregnancy dating established by date of last menstruation and by sonographic measurement of the crown-rump length in the first trimester, and gestational age from 20 to 40 weeks. Exclusion criteria were intruterine death. Each patient was scanned once during pregnancy after written consent. The study prospective protocol was approved by the local hospital's Ethics Committee.

Acquisition and measurement of the placental vascular indices done with Voluson E-10 ultrasound machine (GE Medical Systems, Milwaukee, WI, USA) equipped with a 4-8 MHz transducer was used for 3D scanning. Using the instrument power settings (Angio mode: cent; smooth: 4/5;FRQ: low; quality ; pulse repetition frequency: 1.3). In all cases, independent of gestational age, Power Doppler was applied to obtain images of the placental vasculature. The longest view of the placenta was identified by 2D-ultrasound and the volume box was adjusted in order to scan the entire placenta, with maximum adjusted resolution to scan the whole placenta. The angle of volume sampling varied throughout gestation, from 45 to 90 . When placenta was located posteriorly or in the third trimester of gestation, a slight laterally inclination of the transducer was performed either to avoid acoustic shadowing due to fetal position or to acquire the entire placenta despite of the organ position in uterus and the gestational age. After scanning the entire volume, the three orthogonal ultrasound sections 
were analyzed and stored on a removable hard disk (Figure 4).

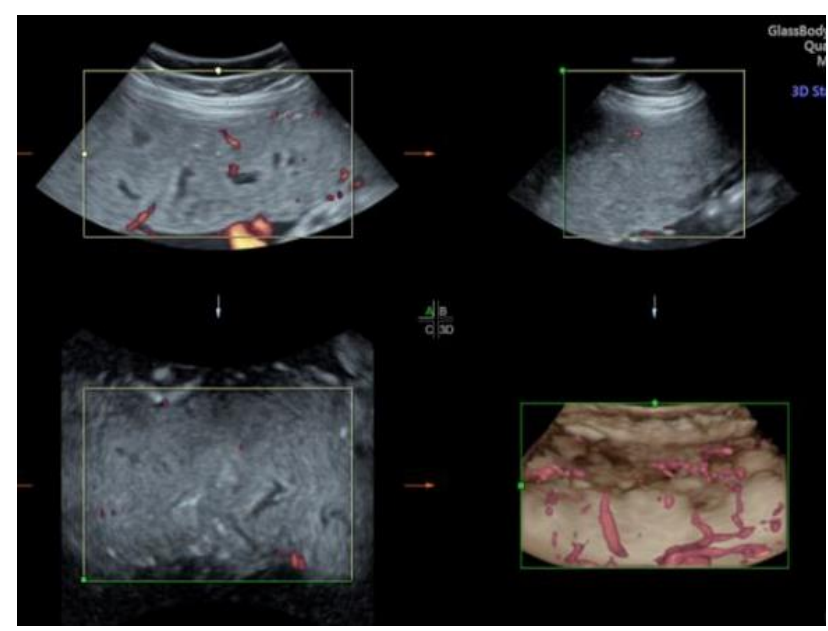

Figure 4: Acquisition of Placental Volume.

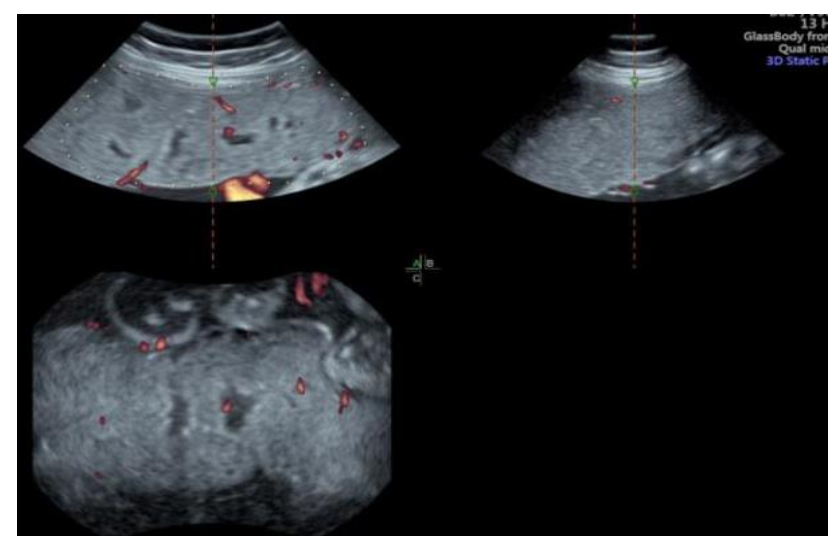

Figure 5: Estimation of placental volume after rotating image $6 x$ by $30^{\circ}$.

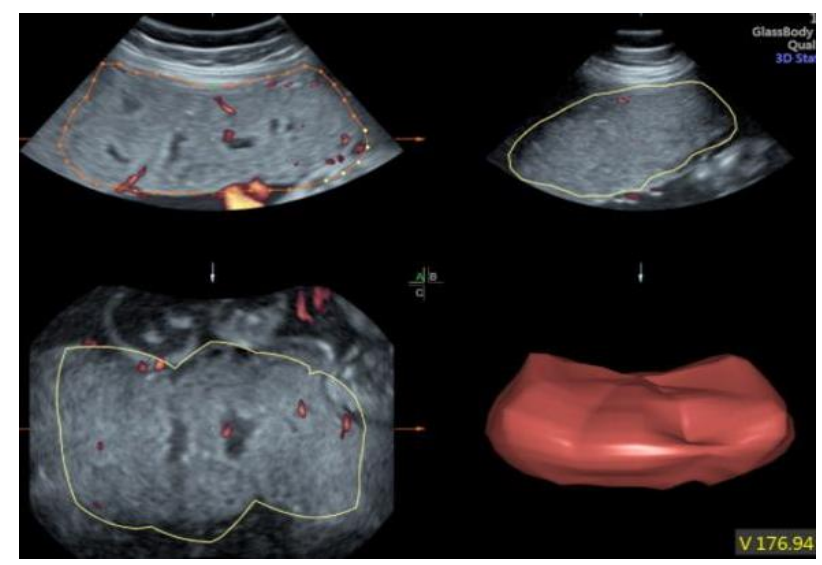

Figure 6: Estimation of placental volume.

The placenta was carefully identified in the three orthogonal multiplanar imaging. The longest view of placenta on A plane of the three orthogonal ultrasound sections was chosen as the reference image. The volume was then measured by the rotational technique using
VOCAL_ software (3D Sono View, GE Medical Systems, Milwaukee, WI, USA), which consists of outlining the contour of the placenta repeatedly after rotating its image six times by 30 degree (Figure 5).

After finishing the complete rotation, placental volume was automatically provided by the software (Figure 6). After estimation of the placental volume, the 3D-power Doppler histogram was used to determine vascular indices from computer algorithms (Figure 7).

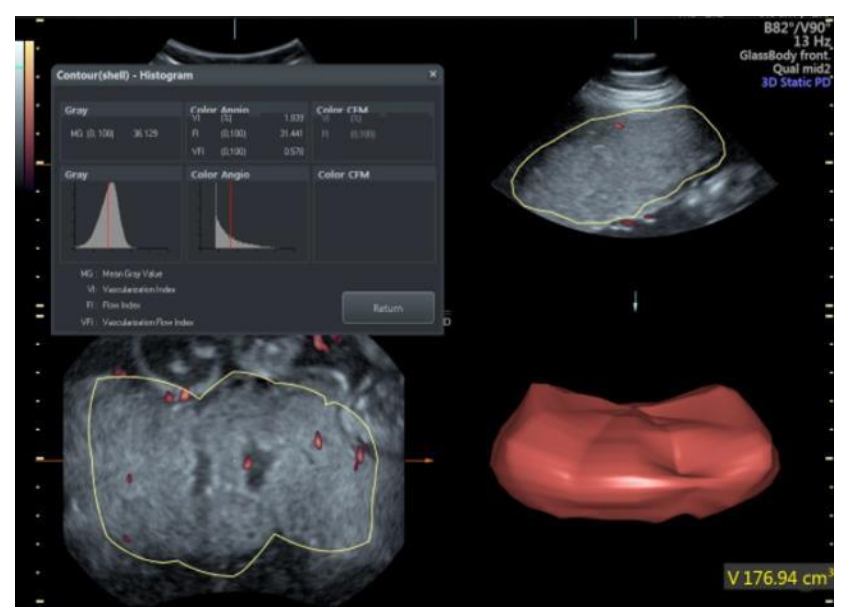

Figure 7: 3D Power Doppler histogram determine VI, FI and VFI.

\section{The vascular indices determined were}

1. Vascularization index (VI), which refers to the color voxel/total voxel ratio, i.e., the color percentage within the volume of interest (placenta), which provides an indication of how many vessels can be detected within the placenta (vascularity).

2. Flow index (FI), which refers to the weighted color voxel (on a scale of $0-100$ )/total color voxel ratio and provides an amplitude value for the color signal, thus providing information on how many blood cells are being transported at the time of the 3D sweep (placental blood flow).

3. Vascularization-flow index (VFI), which refers to the weighted color voxel/total voxel ratio, combining the information of vessel presence (vascularity) and amount of transported blood cells (blood flow).

For each patient, placental vascular indices. Umbilical Doppler was measured with fetal biometry, umbilical arterial S/D ratio (SDR): systolic velocity / diastolic velocity, pulsatility index (PI) and resistive index (RI).

\section{RESULTS}

Total 200 patient were evaluated with exclusion criteria, 182 patients had no complication and 18 patients were detected as intrauterine fetal growth retardation. 
Table 1: Correlation between placental vascular indices and placental position.

\begin{tabular}{|lllll|}
$\begin{array}{l}\text { Placental } \\
\text { position }\end{array}$ & anterior & Fundal & posterior & $\begin{array}{l}\text { P } \\
\text { values }\end{array}$ \\
\hline VI & 2.18 & 3.91 & 3.86 & $<0.01 *$ \\
& \pm 1.84 & \pm 2.38 & \pm 2.50 & \\
\multirow{2}{*}{ FI } & 32.16 & 36.30 & 35.05 & $<0.01^{*}$ \\
& \pm 5.45 & \pm 4.35 & \pm 6.18 & \\
\multirow{2}{*}{ VFI } & 0.76 & 1.53 & 1.40 & $<0.01^{*}$ \\
& \pm 0.73 & \pm 0.91 & \pm 1.06 & \\
\hline
\end{tabular}

Mean maternal age was 27.6 (range: 19-43) years. Placental location (Table 1) was ant in 116 patients, post in 65 patients and fundal in 19 patients. Placental position anterior measured vascular index $(2.18 \pm 1.84)$, flow index $(32.16 \pm 5.45)$ and vascular flow index $(0.76 \pm 0.73)$, Posterior placental position measured vascular index (3.86 \pm 2.50$)$, flow index $(35.05 \pm 6.18)$ and vascular flow

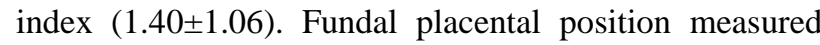
vascular index $(3.91 \pm 2.38)$, flow index $(36.30 \pm 4.35)$ and vascular flow index $(1.53 \pm 0.91)$. Placental position at fundal region shows higher value of VI, FI and VFI.

Table 2: Correlation between placental vascular indices and gestational age.

\begin{tabular}{|llll|l|}
\hline $\begin{array}{l}\text { Placental } \\
\text { vascular } \\
\text { indices }\end{array}$ & & VI & FI & VFI \\
\hline \multirow{3}{*}{ GA } & $\begin{array}{l}\mathrm{r} \\
\text { (correlation } \\
\text { coefficient) }\end{array}$ & -0.022 & 0.007 & -0.024 \\
\cline { 2 - 5 } & P value & $0.75(\mathrm{~ns})$ & $0.92(\mathrm{~ns})$ & $0.73(\mathrm{~ns})$ \\
\hline
\end{tabular}

Table 3: Correlation between placental vascular indices and placental volume.

\begin{tabular}{|llll|l|}
\hline $\begin{array}{l}\text { Placental } \\
\text { vascular } \\
\text { indices }\end{array}$ & VI & FI & VFI \\
\hline $\begin{array}{l}\text { Placental } \\
\text { volume }\end{array}$ & $\begin{array}{l}\mathrm{r} \\
\text { (correlation } \\
\text { coefficient) }\end{array}$ & +0.25 & +0.15 & +0.22 \\
\cline { 2 - 5 } & P value & $<0.01^{*}$ & $0.03^{*}$ & $<0.01^{*}$ \\
\hline
\end{tabular}

Placental position with relation to VI, FI and VFI shows statistically significant with $\mathrm{p}$ value $<0.01$. Placental vascular indices tend to be constant throughout the gestational age (Table 2) but no significant correlation was observed, VI with GA correlation coefficient $(\mathrm{r}=$ $0.022)$, FI with GA ( $r=-0.007)$ and VFI $(r=-0.024)$.

Table 4: Correlation between placental vascular indices and SD ratio.

\begin{tabular}{|c|c|c|c|c|}
\hline & & VI & FI & VFI \\
\hline \multirow[t]{2}{*}{ SD } & $\begin{array}{l}\mathrm{r} \\
\text { (correlation } \\
\text { coefficient) }\end{array}$ & -0.19 & -0.15 & -0.18 \\
\hline & $\mathrm{P}$ value & $<0.01^{*}$ & $0.04 *$ & $0.10(\mathrm{NS})$ \\
\hline
\end{tabular}

Table 5: Correlation between placental vascular indices and pulsatility index.

\begin{tabular}{|c|c|c|c|c|}
\hline & & VI & FI & VFI \\
\hline \multirow[t]{2}{*}{ PI } & $\begin{array}{l}\mathrm{r} \\
\text { (correlation } \\
\text { coefficient) }\end{array}$ & -0.21 & -0.16 & -0.19 \\
\hline & $\mathrm{P}$ value & $<0.01 *$ & $0.03 *$ & $<0.01 *$ \\
\hline
\end{tabular}

Table 6: Correlation between placental vascular indices and Resistive index (RI).

\begin{tabular}{|c|c|c|c|c|}
\hline & & VI & FI & VFI \\
\hline \multirow[t]{2}{*}{ RI } & $\begin{array}{l}\mathrm{r} \\
\text { (correlation } \\
\text { coefficient) }\end{array}$ & -0.16 & -0.13 & -0.15 \\
\hline & $\mathrm{P}$ value & $0.03 *$ & $\begin{array}{l}0.06 \\
(\mathrm{NS})\end{array}$ & $0.03 *$ \\
\hline
\end{tabular}

Table 7: Correlation between placental vascular indices, intrauterine growth retarded fetus (IUGR) and normal fetus.

\begin{tabular}{|llll|}
\hline Fetus & Normal & IUGR & P values \\
\hline VI & $2.88 \pm 2.33$ & $3.10 \pm 1.60$ & $0.70($ NS) \\
\hline FI & $33.45 \pm 5.98$ & $34.61 \pm 3.95$ & $0.27($ NS) \\
\hline VFI & $1.04 \pm 0.96$ & $1.09 \pm 0.57$ & $0.84($ NS) \\
\hline
\end{tabular}

Statistically not significant as $\mathrm{p}$ value $>0.05$ (Figure 8 (a, $\mathrm{b}, \mathrm{c})$ ). Relation of placental vascular indices with volume (Table 3), vascular index $(\mathrm{r}=+0.25)$, flow index $(\mathrm{r}=$ $+0.15)$ and vascular flow index $(r= \pm 0.22)$, shows positive poor correlation. $\mathrm{p}$ value $<0.01$ shows statistically significance. VI, FI. VFI increases with increase in volume (Figure $9(\mathrm{a}, \mathrm{b}, \mathrm{c})$ ). Placental vascular indices VI, FI and VFI (Table 4) when co-related with systolic/ diastolic ratio of umbilical artery shows poor negative correlation, VI $(r=-0.19)$ FI $(r=-0.15)$ VFI $(r=-$ 0.18 ), only VI and FI shows statistically significant as $\mathrm{p}$ value is $<0.01$ and $<0.04$.

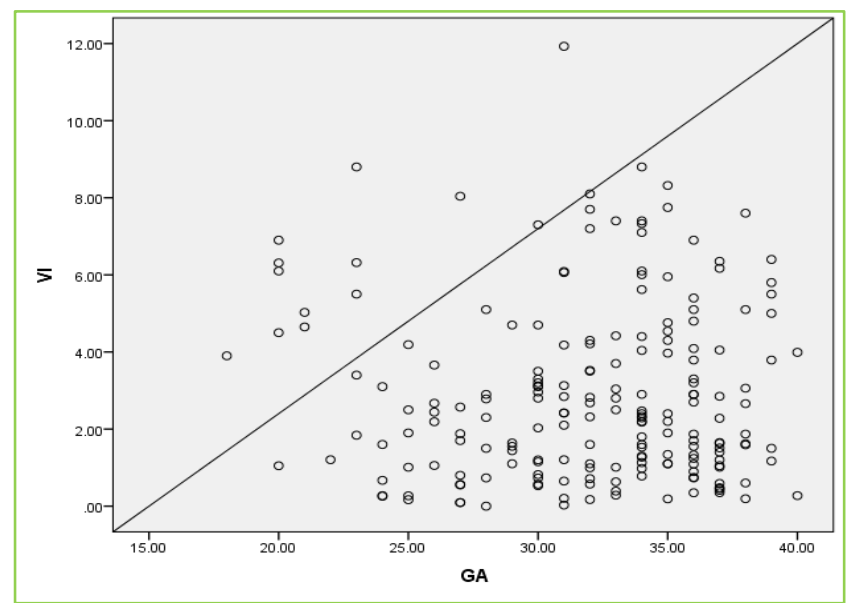

Non-significant as $\mathrm{p}$ value $>0.05$, correlation coefficient is $(\mathrm{r}=-$ $0.022)$.

Figure 8a: Vascular index (VI) tends to be constant gestational age (GA). 


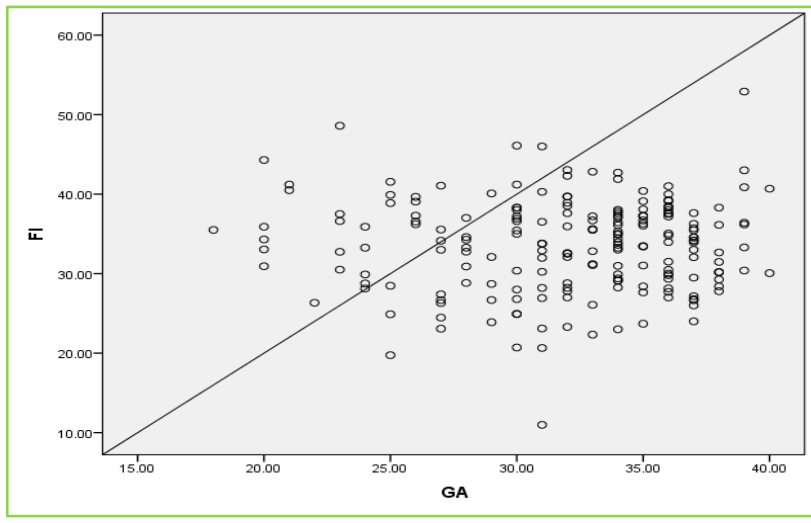

Non-significant as $p$ value $>0.05$, correlation coefficient is $(r=-$ 0.007).

Figure 8b: Flow index (FI) tends to be constant gestational age (GA).

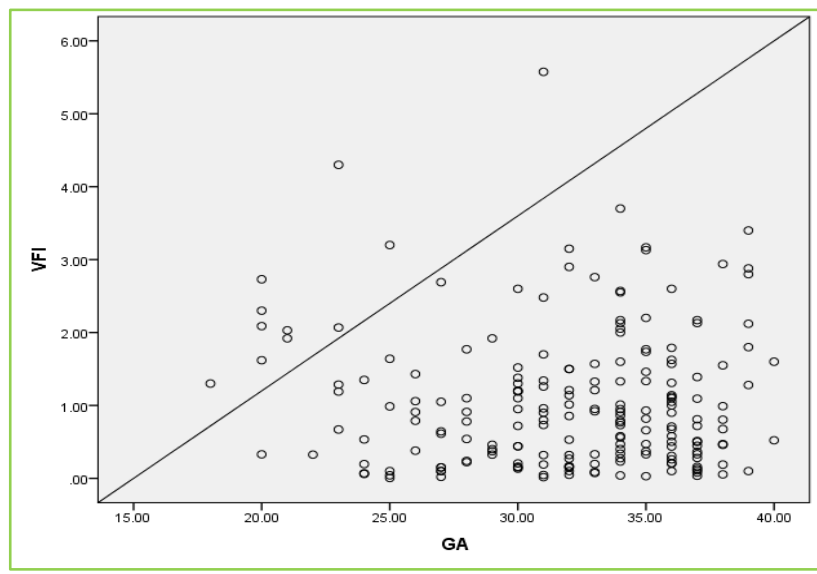

Non-significant as $\mathrm{p}$ value $>0.05$, correlation coefficient is $(\mathrm{r}=-$ $0.024)$

Figure 8c: Vascular flow index (VFI) tends to be constant gestational age (GA).

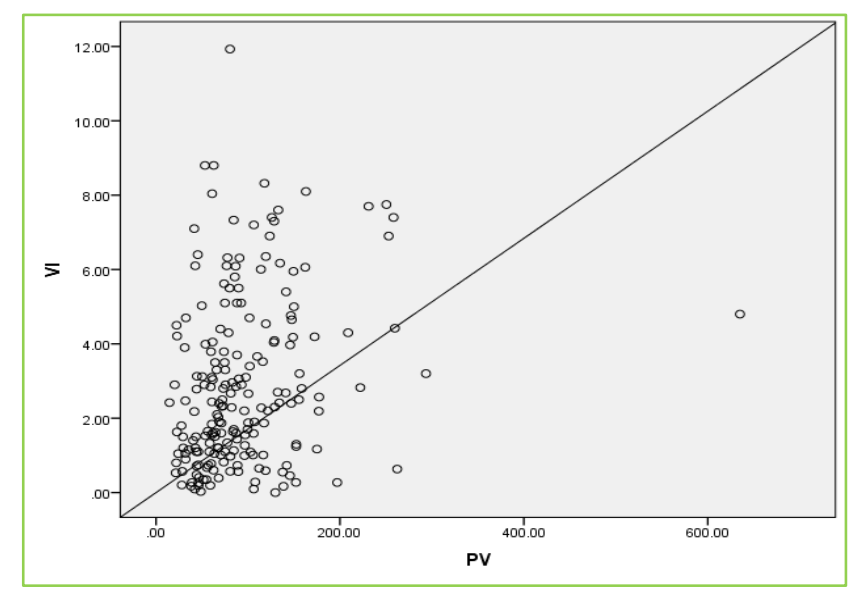

statistically significant as $\mathrm{p}$ value $<0.01$

Figure 9a: Vascular index (VI) tends to show positive poor correlation with placental volume (PV).

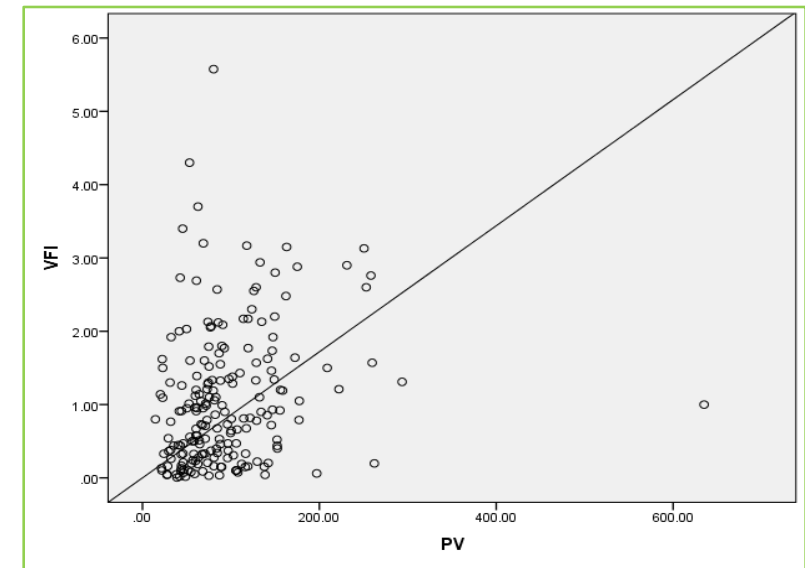

$\mathrm{p}<0.01$ (statistically significant).

Figure 9b: Vascular flow index (VFI) tends to show positive poor Correlation $(r=+0.15)$ with placental volume (PV).

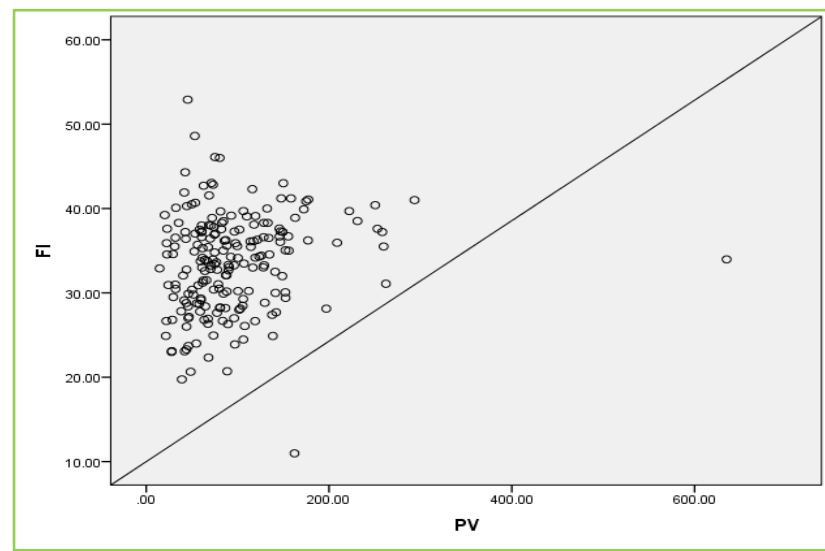

Statistically significant as $\mathrm{p}$ value $<0.01$ correlation coefficient is $(\mathrm{r}=+0.015)$

Figure 9c: Flow index (FI) tends to show positive poor correlation with placental volume (PV).

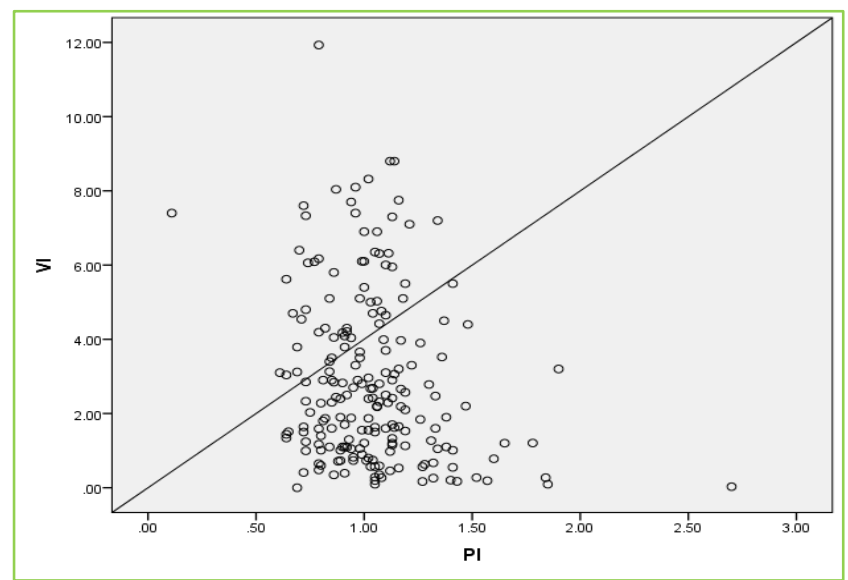

$\mathrm{p}<0.01$ (statistically significant)

Figure 10a: Vascular index tends to show negative poor Correlation $(r=-0.21)$ with pulsatile index. 


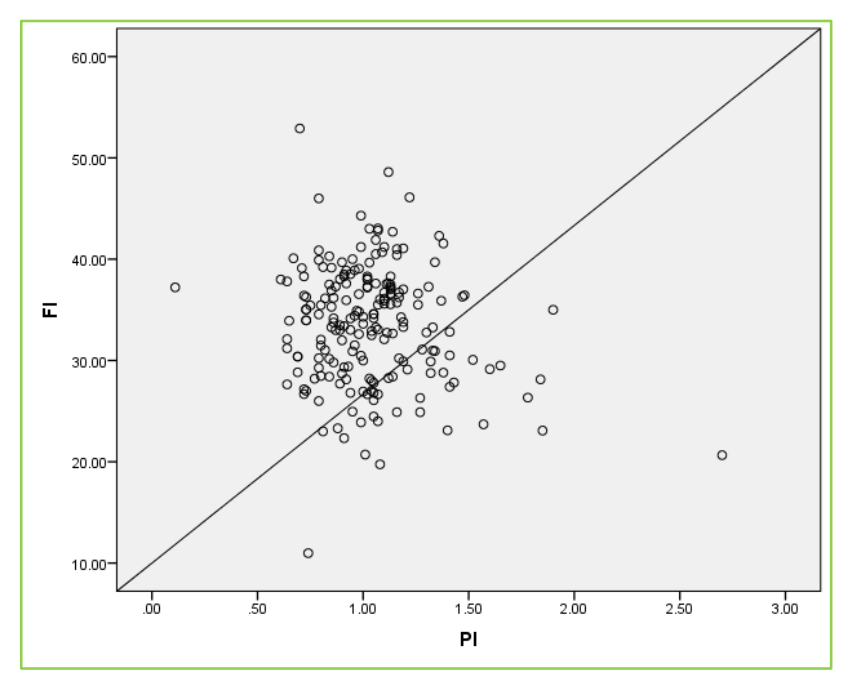

$\mathrm{p}<0.01$ (statistically significant)

Figure 10b: Flow index tends to show negative poor Correlation $(r=-0.16)$ with pulsatile index.

VFI did not show statistically significant as $\mathrm{p}$ value is 0.10(NS). Pulsatility index correlated (Table 5) VI ( $\mathrm{r}=-$ $0.21), \mathrm{FI}(\mathrm{r}=-0.16)$ and VFI $(\mathrm{r}=-0.19)$ shows poor negative correlation. But $\mathrm{p}$ value is stastically significant is less than $<0.01$ (Figure $10(a, b, c)$ ).

Resistivity index correlated (Table 6) VI ( $\mathrm{r}=-0.16-)$, FI $(\mathrm{r}=-0.13)$ and VFI $(\mathrm{r}=-0.15)$ shows negative correlation.

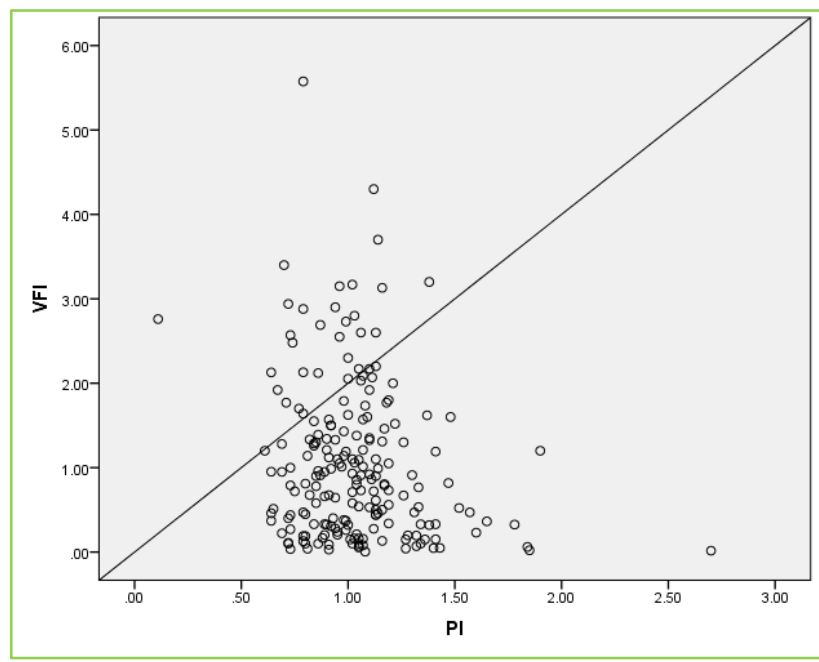

$\mathrm{p}<0.01$ (statistically significant)

Figure 10c: Vascular flow index tends to show negative poor Correlation $(r=-0.19)$ with pulsatile index.

But $\mathrm{p}$ value is statically significant is less than $<0.01$ for VI and VFI but not significant with FI as p value is 0.06 . The placental vascularity index values of fetal growth retarded (FGR) pregnancies (Table 7) were compared with normal pregnancy. VI for FGR $(3.10 \pm 1.60)$ and normal pregnancy (2.88 \pm 2.33$)$, FI for FGR (34.61 \pm 3.95$)$ and normal pregnancy $(33.45 \pm 5.98)$ VFI for FGR
$(1.09 \pm 0.57)$ and normal pregnancy $(1.04 \pm 0.96)$ but it not statistically significant as $\mathrm{p}$ value is $>0.05$.

\section{DISCUSSION}

Analysis of the results showed that the placental vascular indices estimated by 3D-power doppler ultrasonography presented constant distribution throughout gestation, despite the significant increase in placental volume. This fact suggests that placental vascularization (number of vessels and blood flow) may increase proportionally to the organ volume, contributing to maintaining the placental vascular indices constant throughout gestation, as revealed by the 3D-power Doppler histograms.

All placental vascular indices (VI, FI and VFI) were constant throughout gestation in normal pregnancies despite the increase in placental volumes. ${ }^{9}$ which means that the organ studied showed an increase in size proportional to the development of its vascular status (number of vessels and amount of flow). This physiological mechanism is translated by the constancy of the 3D power Doppler vascular indices throughout gestation. In this study relation of placental vascular indices with volume shows poor positive co-relation but statistically significant.

There have been few studies on 3D power Doppler indices in the placenta between normal and FGR pregnancies. Guiot et al studied 45 pregnant women (15 normal and 30 FGR pregnancies) at 23-37 weeks' gestation. ${ }^{10}$ They found that VI and VFI were significantly lower in FGR pregnancies with abnormal patterns but with positive end-diastolic umbilical artery flow velocity waveforms (PED) and absent or reversed end-diastolic umbilical artery flow velocity waveforms (AED) compared with normal pregnancies, while FI decreased only in the AED group and suggested that FI appears to be the most reliable index because of its low intraplacental variability.

VI, FI, and VFI in FGR pregnancies decreased by $61.5 \%$, $7.7 \%$, and $46.2 \%$ throughout pregnancy, respectively. With respect to the third trimester, VI, FI, and VFI values in FGR pregnancies were significantly lower than those in normal pregnancies. ${ }^{11}$ In present study Placental vascular indices VI, FI and VFI when corelated with systolic/ diastolic ratio, pulsaltile index and resistivity index of umbilical artery shows poor negative correlation, only VI and FI shows statistically significant with SD ratio as $\mathrm{p}$ value is $<0.01$ and $<0.04$. VFI did not show statistically significant as $\mathrm{p}$ value is $0.10(\mathrm{NS})$.

With pulsatility index $\mathrm{p}$ value is statistically significant is less than $<0.01$ with vascular indices. Resistive index $\mathrm{p}$ value is stastically significant is less than $<0.01$ for VI and VFI but not significant with FI as $p$ value is 0.06 . The placental vascularity index values of fetal growth retarded (FGR) value is higher than normal pregnancy, but it not statistically significant as $\mathrm{p}$ value is $>0.05$. 
Moreover, an entirely visualized anterior placenta was included to keep the maximum depth of the placenta constant, as Raine-Fenning et al reported that there was a significant reduction in each index as the distance between the transducer and vessel increased. ${ }^{12}$ Zalud et al stressed that only anterior placentas were included in their study to avoid the risk of Doppler signal attenuation. ${ }^{13}$ Paula-Ruano et al observed that there was no difference in placental vascular indices in accordance to the organ position despite the fact that power-Doppler signal may change according to the tissue depth. ${ }^{5}$ This fact can be explained by the technique of acquisition of the placental volume, in which a slight laterally inclination of the transducer was performed in order to place the placenta more proximal to the transducer.

Authors also used the VOCAL- program with a rotation of 30- since it was observed that it can provide results with lower intra and inter-observer variabilities but being easier and faster. ${ }^{14}$ In this study placental position at fundal region shows higher value of VI, FI, and VFI. Placental position with relation to VI, FI, and VFI shows statistically significant with stastically value $<0.01$. A possible limitation of 3D power Doppler measurements could be the equipment and setting used in the study. Raine-Fenning et al demonstrated that the VI, FI and VFI are all affected significantly by variations in power Doppler settings and by the speed of acquisition, while the gain and signal power have the greatest effect on the power Doppler signal, followed closely by the PRF. The other settings and speed of acquisition also influenced the signal, but to a much lesser degree. ${ }^{15}$ But in present study electronic probe was used which minimizes the influence of signal and speed of acquisition.

\section{CONCLUSION}

The placental vascular indices determined by analysis of the 3D-power Doppler histograms revealed constant indices according to gestational age, placental vascular sonobiopsy using 3D power Doppler ultrasound assists in the evaluation of placental vascularization in normal and FGR pregnancies.

It may play an important role in future research on fetoplacental insufficiency for diagnosing pregnancies at high risk for preeclampsia, fetal growth restriction and placental insufficiency.

Funding: No funding sources

Conflict of interest: None declared

Ethical approval: The study was approved by the Institutional Ethics Committee

\section{REFERENCES}

1. Brosens JJ, Pijnenborg R, Brosens IA. The myometrial junctional zone spiral arteries in normal and abnormal pregnancies: a review of the literature. Am J Obstetr Gynecol. 2002 Nov 1;187(5):1416-23.
2. Konje JC, Huppertz B, Bell SC, Taylor DJ, Kaufmann P. 3-dimensional colour power angiography for staging human placental development. Lancet. 2003 Oct 11;362(9391):1199201.

3. Coleman MA, McCowan LM, North RA. Midtrimester uterine artery Doppler screening as a predictor of adverse pregnancy outcome in high-risk women. Ultrasound Obstetr Gynecol. 2000 Jan;15(1):7-12.

4. Guiot C, Gaglioti P, Oberto M, Piccoli E, Rosato R, Todros T. Is three-dimensional power Doppler ultrasound useful in the assessment of placental perfusion in normal and growth-restricted pregnancies?. Ultrasound Obstetr Gynecol. 2008 Feb;31(2):171-6.

5. De Paula CF, Ruano R, Campos JA, Zugaib M. Quantitative analysis of placental vasculature by three-dimensional power Doppler ultrasonography in normal pregnancies from 12 to 40 weeks of gestation. Placenta. 2009 Feb 1;30(2):142-8.

6. Kinzler WL, Vintzileos AM. Fetal growth restriction: a modern approach. Current Opin Obstetr Gynecol. 2008 Apr 1;20(2):125-31.

7. Campbell S. Placental vasculature as visualized by 3D power Doppler angiography and 3D color Doppler imaging. Ultrasound Obstetr Gynecol. 2007 Nov;30(6):917-20.

8. Mercé LT, Barco MJ, Bau S, Kupešić S, Kurjak A. Assessment of placental vascularization by threedimensional power doppler" vascular biopsy" in normal pregnancies. Croatian Med J. 2005 Oct $1 ; 46(5)$.

9. de Paula CF, Ruano R, Campos JA, Zugaib M. Placental volumes measured by 3-dimensional ultrasonography in normal pregnancies from 12 to 40 weeks' gestation. J Ultrasound Med. 2008;27:158390

10. Guiot C, Gaglioti P, Oberto M, Piccoli E, Rosato R, Todros T. Is three-dimensional power Doppler ultrasound useful in the assessment of placental perfusion in normal and growth-restricted pregnancies?. Ultrasound Obstetr Gynecol. 2008 Feb;31(2):171-6.

11. Noguchi J, Hata K, Tanaka H, Hata T. Placental vascular sonobiopsy using three-dimensional power Doppler ultrasound in normal and growth restricted fetuses. Placenta. 2009 May 1;30(5):391-7.

12. Raine-Fenning NJ, Nordin NM, Ramnarine KV, Campbell BK, Clewes JS, Perkins A, Johnson IR. Determining the relationship between threedimensional power Doppler data and true blood flow characteristics: an in-vitro flow phantom experiment. Ultrasound Obstetr Gynecol. 2008 Sep;32(4):540-50.

13. Zalud I, Shaha S. Three-dimensional sonography of the placental and uterine spiral vasculature: Influence of maternal age and parity. J Clin Ultrasound. 2008 Sep;36(7):391-6.

14. Nowak PM, Nardozza LM, Júnior EA, Rolo LC, Moron AF. Comparison of placental volume in early 
pregnancy using multiplanar and VOCAL methods. Placenta. 2008 Mar 1;29(3):241-5.

15. Raine-Fenning NJ, Nordin NM, Ramnarine KV, Campbell BK, Clewes JS, Perkins A, Johnson IR. Evaluation of the effect of machine settings on quantitative three-dimensional power Doppler angiography: an in-vitro flow phantom experiment. Ultrasound Obstetr Gynecol. 2008 Sep;32(4):551-9.
Cite this article as: Choudhary S, Mishra V, Aggarwal R, Mistry K. Evaluation and correlation of placental vasculature by three-dimensional power Doppler ultrasonography with umbilical Doppler in normal and IUGR pregnancies. Int J Reprod Contracept Obstet Gynecol 2018;7:3818-25. 